Yuri Carvajal Bañados

Escuela de Salud Pública - Universidad de Chile

ycarvajal61@gmail.com

\title{
La revolución política de Chili tras 500 años de antropoceno
}

\author{
The Chili's politics revolution after 500 years of Anthropoceno
}

\begin{abstract}
Resumen
El artículo elabora un análisis de las últimas manifestaciones políticas de Chile bajo la perspectiva de una crisis cosmopolítica que se comprende como Antropoceno, una epoca geológica determinada por la acción humana. Es posible entonces denominar revolución al acontecimiento, expresión de una crisis climático-ambiental de vigencia ineludible. En ese sentido se trata de la inscripción de la reciente revolución política en el marco de un agotamiento de las categorías que han estructurado el ordenamiento político moderno y que invita a la consideración de un nuevo esquema político donde la naturaleza, la animalidad, la geología y otros elementos "no representados" tomen parte activa de la conformación política y social. No es el último movimiento político, sino uno de los primeros.
\end{abstract}

Palabras clave: Revolución, Antropoceno, Chile

\begin{abstract}
The article elaborates an analysis of the latest political manifestations of Chile under the perspective of a cosmopolitical crisis that is understood as Anthropocene, a geological epoch determined by human action. It is possible then to call the event a revolution, an expression of a climate-environmental crisis of inescapable validity. In this sense, it is about the inscription of the recent political revolution in the framework of an exhaustion of the categories that have structured the modern political order and that invites to the consideration of a new political scheme where nature, animality, geology and other "not represented" elements take active part of the political and social conformation. It is not the last political movement, but one of the first.
\end{abstract}

Keywords: Revolution, Anthropocene, Chili

\section{Introducción}




\section{Yuri Carvajal Bañados}

Durante un buen pedazo del siglo XXI nos preguntamos si acaso tenía sentido interrogar el valor de la palabra revolución. Leyendo junto a los estudiantes el Marat-Sade (Weiss, 2010), en un curso de formación general, intentamos dialogar esta inquietud. Los intercambios fueron valiosos, vivos, pero poco concluyentes. Sólo sentíamos que la pregunta era verdadera como sólo las quaestio (Coccia, 2008) pueden serlo.

Encontramos - en medio de los acontecimientos- una referencia foucaultiana que nos dio nuevo aire. Habíamos sentido el gesto suyo en las calles en medio de los chicos que ahogaban una lacrimógena en una balde de agua, una insolencia frente a las armaduras y al crimen con que la mentira y la injusticia suele arroparse. La cita no tardó en venir:

“[...] yo diría, de envidia cultural: no van a ser ellos los que hagan una verdadera revolución según su propio estilo si nosotros no pudimos hacerla según el nuestro! Nosotros, que inventamos la idea de la revolución, que la elaboramos, nosotros que organizamos todo un saber, todo un sistema político, todo un mecanismo de partidos, etc., en torno a esta idea de revolución. Bueno, se puede dar esta explicación. No estoy seguro de que sea cierto” (Bardet y Gago, 2019)

En esos mismos días conocimos la conferencia que Lazzarato (2019) envió al VII Coloquio Latinoamericano de Biopolítica y nos enteramos del eurocentrismo de Foucault y sus lamentables olvidos. Como Cortázar, cuando le dijeron que los discos que escuchaban los personajes de Rayuela jamás existieron, sólo atinamos a arroparnos bajo unas frazadas para llorar la pena. Pero la aparición de la cita anterior nos mostró que la crítica era injusta.

Aceptado entonces el derecho a hablar de revolución, para nombrar un acontecimiento que rompe el tiempo, no para repetir ideas europeas sino con las cuestiones empíricas que la realidad a menudo oculta en su abrumador sentido común, en sus frases hechas, en sus metáforas mediocres, podemos entonces hablar de revolución, aunque sea como un despertar, figura que puede tener varios sentidos: 


\section{Yuri Carvajal Bañados}

- Abrir los ojos, ver un nuevo orden tras el orden aparente, recomponer una nueva gestalt, una imagen otra que empieza a delinearse.

- $\quad$ Pasar de la horizontalidad propia a un encuentro con otros, erguirse, caminar, poner el cuerpo, pisar tierra, reconocer la pobreza semicolonial de un país austero.

- Detenerse un largo rato en esas medias aguas del silencio y la contemplación, cuando las ideas apenas afloran suspender el juicio, dejarse llevar por el acontecimiento.

Despertar y sentir que estamos en medio de una revolución. Los viejos libros enseñaban que las revoluciones no eran un instante, sino una marcha de años. La revolución como despertar puede ayudarnos a combinar esa larga marcha con la irrupción de lo súbito. Cuando miles y cientos de miles entran en política para inaugurar un tiempo de matar dragones escolásticos. El gesto del campesino que no se aparta en la calle al paso del señor, seña indiciaria de algo que ya ha ocurrido pero también de que aún resta demasiado por venir. Un hecho nuevo, pero a la vez cargado de citas, como el robo de los punteros del reloj de flores en Avenida Marina (Benjamin, 2012).

Intento leer los signos de Chili $^{1}$ en medio de ese aire respirable pese a los humos lacrimógenos, al borde de cumplirse 500 años del paso de Magallanes por el estrecho, de la llegada del Antropoceno, esa introducción de la heterotopía máxima en nuestro suelo, en barcos que fueron al decir de Foucault "no solamente el instrumento más grande de desarrollo económico (no es de eso de lo que hablo hoy), sino la más grande reserva de imaginación. El navío es la heterotopía por excelencia” (Foucault, 1967).

Entonces resulta urgente decir que esta revolución política es una revolución antropocénica. Así lo han dicho Jaime Hurtubia (Hurtubia, 2019), Paola Bolados (Bolados, 2019), el Instituto Mileno Oceanográfico (Instituto Milenio de Oceanografía, 2019) señalando que se trata de un mismo proceso.

Una revolución de una nueva época, por eso no valen los calificativos de social, ni de "millennials". Estamos en medio de una revolución geológica, no por nada le arrojaron a los

\footnotetext{
$1 \quad$ Uso este nombre patrio, presente en mapas del siglo XVII (Mapa de Willem Blaeu 1662), pero también como homenaje a Ignacio Molina, que habló de Chilidugu,Chilihueques y Chileños, en su Historia Geográfica, Natural y Civil del Reyno de Chile
}

RE-PRESENTACIONES. Investigación en Comunicación

DOI10.35588/rp.v0i12.4316 


\section{Yuri Carvajal Bañados}

policías un fósil de amonite de 66 millones de año en Coyhaique (Instituto Milenio de Oceanografía, 2019). Las piedras, la geología han irrumpido como fuerzas vivientes.

\section{5 signos del antropoceno en la revolución misma}

\section{I Voces de la revolución}

En las calles las pintadas: “animales son hermanes". Voces veganas, animalistas, fin de la excepción humana. Las zonas críticas ondeando sus banderas. Ayer una mujer del primer sector Corvi de Playa Ancha, junto con llamar a formar un partido del pueblo, denuncia que ellos también viven en una zona crítica, pues tienen enfrente el colector de Esval, construido como uno de los argumentos ex post de la privatización del agua. Quiero decir que en medio del movimiento que parece constitucional, que parece social, hay voces que remarcan las cuestiones ambientales como cruciales. También la lucha antipatriarcal que se ha masificado en una estética propia de una revolución real y las voces de los pueblos indígenas, son signos de la tierra. Los cuerpos nos devuelven a la animalidad, esa que el patriarcalismo tanto teme, tanto huye. Podemos ver también al huaso y su caballo, antropoceno puro, imperialismo ecológico (Crosby, 2015). Las estatuas degolladas de los héroes ecuestres. 


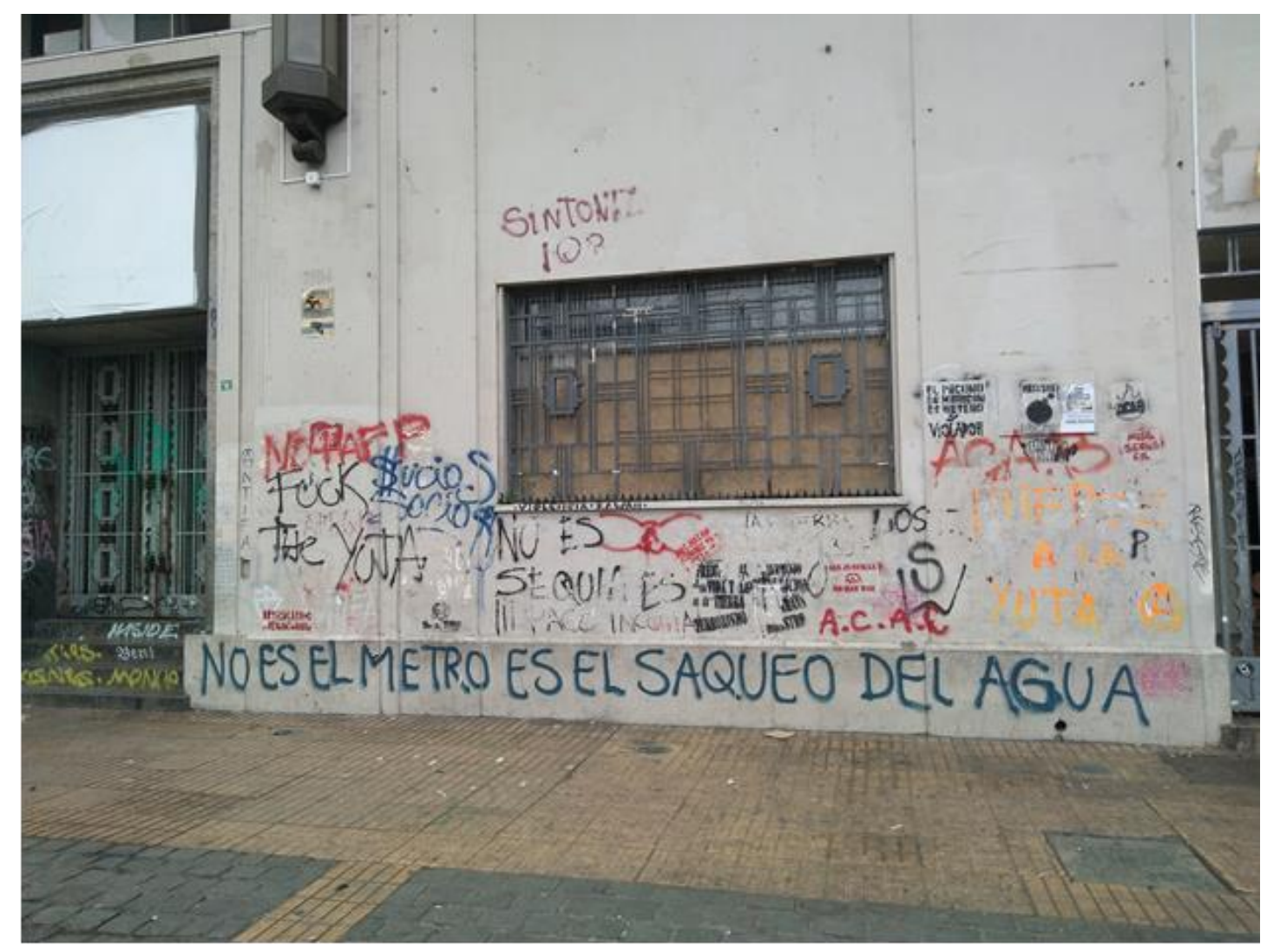

Figura 1 Voces presocráticas en Plaza Aníbal Pinto, Valparaíso

\section{I. I El caso del año 2019 y una chica llamada Greta}

La posibilidad de tener en Chile la COP25 dio nuevas fuerzas al movimiento ambientalista. Había acompañado a Ventanas como editor y pude sentir esa animación. Escuche las voces del agua y los glaciares el sábado 13 de abril en la Facultad de Arquitectura y Urbanismo y palpar las energías vitales. Vi la marcha del 27 de septiembre marcada por la preocupación vegana /vegetariana, con una rotunda y masiva presencia de jóvenes. En agosto tan sólo nos habíamos reunidos para hablar de Calama, Lota, de termoeléctricas y mineras.

\section{I. II EI colapso de la dicotomía social natural}

La tansmutación de valores de esta revolución nos vuelve a la tierra. Las wipalas y el cuaternario del kultrún se enarbolan al viento, diciendo que las líneas sobre las que se escriben los textos oficiales ya se han borrado. Mapuche Vulcano lo ha dicho en twitter mejor que yo. 


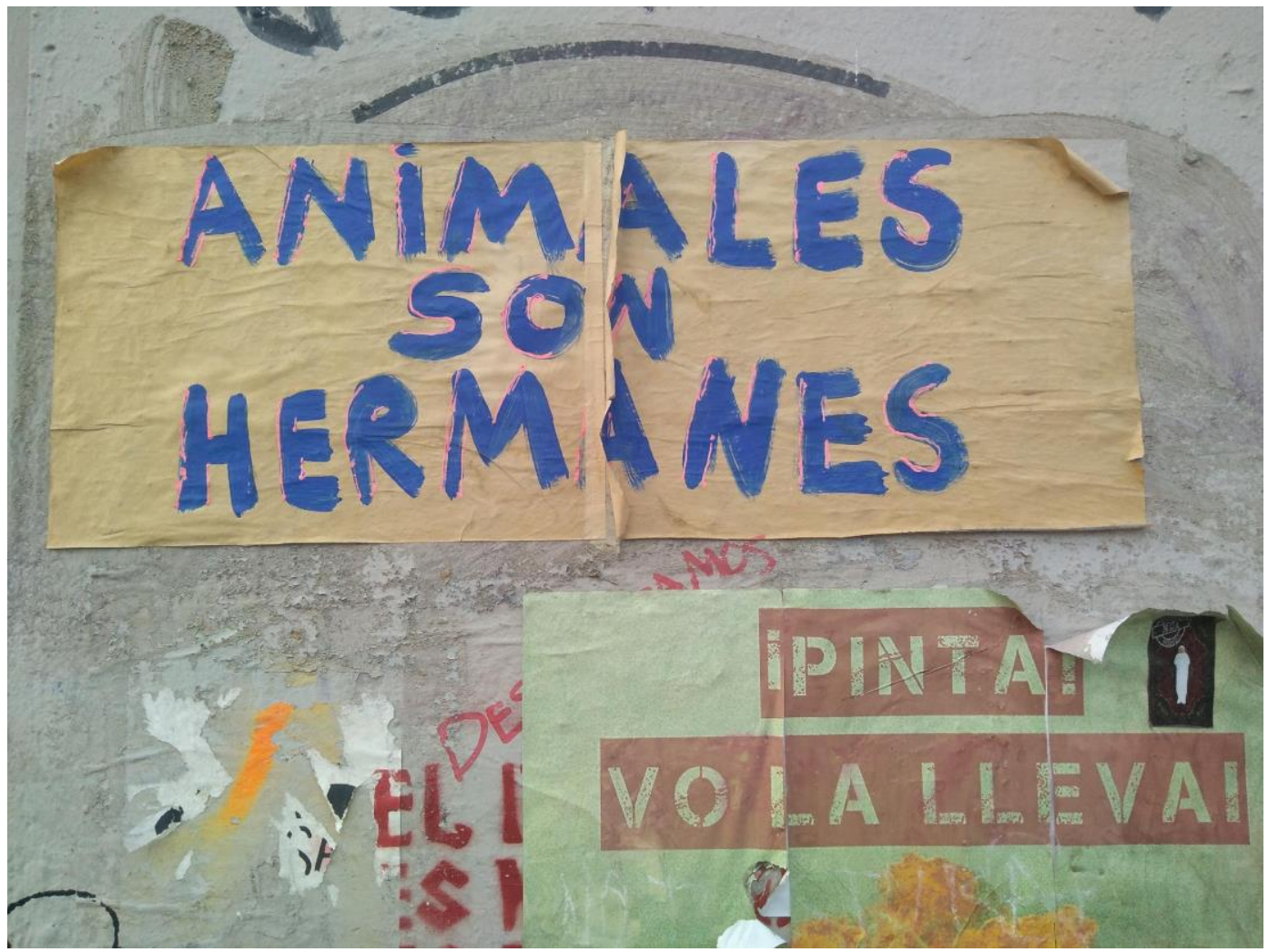

Figura 2 Calle Bernardo O'Higgins, Valparaíso

Los nuevos valores se inscriben a la altura de la mirada, de los ojos, de las bocas, de las manos. Pero también de los perros ("Los reyes") que asoman con pañuelos rojos en el cuello, plenos de política, pidiendo al pueblo que no saquee al pueblo. Perros que no husmean a los chicos detenidos en busca de THC inculpador. También la especie lupus se encuentra fracturada, entre los servidores y los que se niegan a servir. 


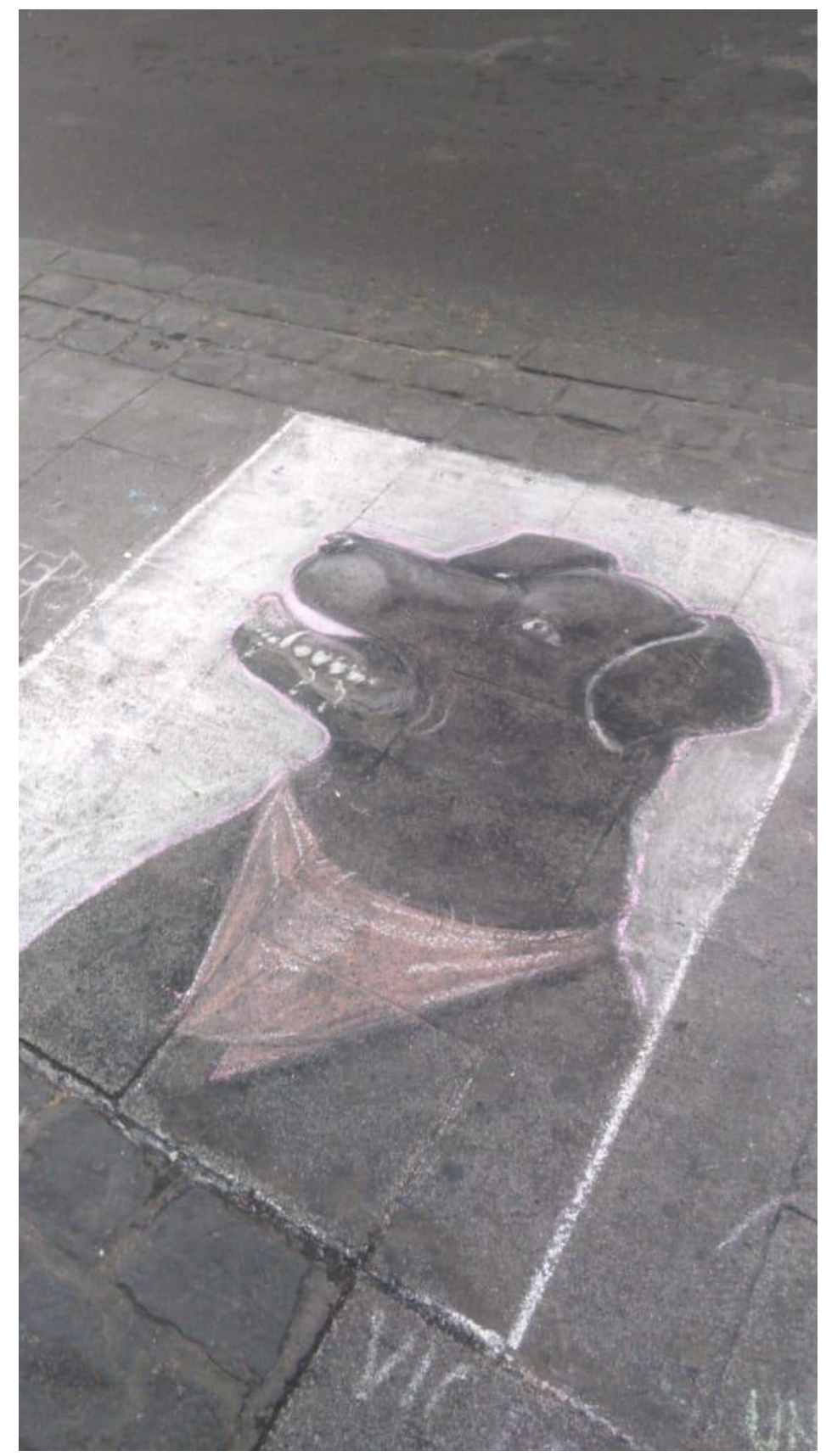

Figura 3 Calle Condell, Valparaíso

Y entretanto el mundo es uno. No hay la sociedad por un lado y el medio ambiente por otro. Esta dicotomía y la palabreja medioambiental, que aunque suena anodina es de máxima toxicidad, han sustentado el sueño de una gerencia/ingeniería ambiental, la ley de bases y el Ministerio del Ambiente, en donde la economía ha sustituido a la ecología. Dos letras de distancia pero un abismo conceptual. 


\section{Yuri Carvajal Bañados}

Esa dicotomía, propia de occidente e impensable en otras epistemologías (Descola, 2011), no sólo miente sino que ha fracasado y está en el corazón de esta crisis.

La crisis es antropocénica, porque en ese complejo nudo de política y Gaia se expresa la cuestión más urgente. 500 años de llegada de occidente a nuestro humus, de extinciones e imperialismo ecológico, 500 años de carbonización mineral, de alambres púas, de ejércitos y policías, de constituciones y ordenamientos.

\section{II.II Las huelgas del transporte, las crisis de la energía}

Pero si todo lo anterior no fuera suficiente, habría que mirar la crisis de 1949 ("huelga de las chauchas"), la del 3 de abril de 1957 ("los luctuosos hechos de abril") y la del 2007 ("transantiago") como crisis del Antropoceno, de la vida urbana en un territorio perturbado, crisis de la energía en la democracia de carbono (Mitchell, 2011) y de los transportes en masa en un ir y venir propios de una gestión de masas. Crisis de los gobiernos pastorales y de los regímenes de policía en los países en vías de subdesarrollo.

Por supuesto que esto reordena nuestra perspectiva histórica y asimismo, nuestra visión política. La Unidad Popular debe ser revisitada si queremos entender la dictadura. Y remirar la UP es volvernos con los ojos del despertar a mirar el siglo XX Chileno y los 500 años de arribo del Antropoceno a nuestro humus.

El gran salto adelante del siglo XX fue acometido brutalmente en nuestro suelo y aun así no fue capaz de generar un consumo masivo. Antes de la Segunda Guerra Mundial nuestra crisis ambiental era alimentaria (Yáñez, 2018). Tras la guerra, se volvió un problema de consumo masivo de línea blanca, electrodomésticos y automóviles: los devenires del área social de Allende y del mismísimo proyecto Synco (Medina, 2013). Pinochet tomó otro camino, pero logró poner uno o dos autos en el antejardín de todos los chilenos. El costo fue sin duda terrible: extractivismo minero y alimentario desenfrenado, un país desertificado y poluído al extremo. Pero nada que ya no hubiera sido visible (Elizalde, 1970).

\section{La gran incomprensión: ¿epistemología, hermeneútica o antropoceno?}




\section{Yuri Carvajal Bañados}

La abismante incompresión que ha acompañado a la revolución, potenciándola desde su sordera, violentándola y multiplicándola, ha sido subrayada por varios analistas. Pero esta vez no se trata sólo de aislamiento, de interpretación o de incapacidad cognitiva.

Lo que se juega es un pensamiento del Holoceno versus el pensamiento del Antropoceno. O por decirlo en forma sencilla: inmanentistas versus esencialistas. Aunque también hay que considerar aquello que Latour ha llamado oligópticos (Latour, 2008), es decir que todo lugar de conocimiento es situado y que los tan mentados panópticos no son más que sitios fragmentarios y parciales. Que el todo que ellos consideran es siempre más pequeño que sus partes (Carvajal y Yuing, 2013). Así como la predominancia de los flujos por sobre las estructuras, la pérdida de todas las escalas y distinciones entre micro y macro para aplanar los colectivos.

En suma, una remirada a la vida en común, incorporando a los no humanos y por supuesto, volver la espalda a la historia whig, para buscar en los débiles una fortaleza insospechada, la clave de aquella enigmática cita con que la Arendt encabezó el escrito que no alcanzó a tipear de la tercera parte de la vida del espíritu: La causa victoriosa plugo a los Dioses, pero la vencida, a Catón (Arendt, 2003).

\section{Consecuencias}

\section{Perspectivas del acontecimiento}

Toda hipótesis vale por su carácter predictivo y por su productividad para la acción. Si el real motor de la crisis es ambiental, la cosa va para largo. Su solución no es una mera jugada de palacio o como gustan de decirlo, la cocina de la política (realizada por personas que jamás han cocinado y lavado un verdadero plato). Pero tampoco podría resolverse en un asalto a ese palacio. Estamos en una cosmopolítica, una entrada de Gaia en política y eso hace todo más inestable, incierto e irreductible.

De pronto en el sentido común volvió a aparecer la solidaridad y los colectivos. Los mercados tiemblan, el dólar sube y las leyes de la economía ya no se cumplen. El experimento económico ha devenido en una singularidad política.

Por supuesto que el movimiento es vibrante y tiene más energía que formas. Pero, ojo, lo que está en juego es la vida planetaria, no la herencia de la revolución francesa, en que lo social se separó de lo natural.

RE-PRESENTACIONES. Investigación en Comunicación

DOI10.35588/rp.v0i12.4316 


\section{Yuri Carvajal Bañados}

Esta revolución se ha acumulado en 500 años y conspira contra cualquier engaño moderno. La crisis ha mostrado todo lo amalgamado que está aquello que el hombre occidental ha intentado separar.

\section{La Constitución}

Como un resabio de la dictadura, la Constitución se ha puesto en el centro del problema. Hace 500 años no teníamos constitución y no andábamos tan mal. Pero si una constitución -por las razones que sea- ha de ordenar nuestros problemas, lo será en la medida en que sea tan audaz que casi no pueda llamarse constitución. Serres habla de un contrato natural (Serres, 2004), pero quizás más que constitución deba ser un koyaqtun natural, una instancia de paz con la tierra (Serres, 2004). No importa el nombre, pero de lo que se requiere es pisar la tierra, es decir, repensar el crecimiento económico (¿Por qué Nietzsche no habrá dicho el crecimiento y el progreso han muerto? ¿Por qué tendría que enredarse con Dios?), la industria, los viajes en avión, el consumo de carne.

¿Cómo se escribe una constitución anti patriarcal para que no sea letra muerta? ¿Cómo se hace una constitución plurinacional cuando el $84 \%$ de los chilenos tiene DNA mitocondrial indigena? ¿Cómo se escribe una constitución animista? ¿Cómo se produce una ley en que el agua tenga derechos, como algo viviente? ¿Cómo se inscriben en ese texto nuestra humildad ante los vegetales y en dónde plantamos la voz de los alerces, resucitados de las esquinas en donde aún sostienen cables de electricidad y teléfonos? (Haudricort, 2019).

Preguntas que señalan que los tiempos han de ser mucho más reflexivos y dialogados que los que permite una comisión técnica muy poco técnica (Soto, 2019).

\section{¿Son los indígenas minoría?}

Es verdad que ser indígena no es tener DNA mitrocondrial solamente. Es territorio, historia vital, gesto. No alegaré que basta una muestra de sangre para decirse pueblo indígena. Pero tampoco me parece que la voz originaria pueda resumirse en un número minoritario, de 15 o 19 constituyentes. Discutir el guarismo de un cupo mezquino parece una traición a la fuerza tectónica del presente. Claramente lo originario en Chile no es minoritario. O si no cambiemos el nombre al país y dejemos una minoría de letras que suene a Chili y pongamos la mayoría en 


\section{Yuri Carvajal Bañados}

spanglish. La energía de lo originario no me parece desprendible de la fuerza del agua, el humus, el aire o lo animado. ¿Cómo dar a esa visión su merecida potencia?

Apenas se me ocurre que deberíamos tener una constituyente bicameral, un lugar de propuestas, pero también con toda radicalidad un lugar de veto, restrictivo, de voces originarias, organizadas en forma territorial. Si el mundo presocrático parecía componerse del mismo modo que en los pueblos originarios, es totalmente legítimo que sean esos espacios del mundo, mejor preservados en sus voces y manos, en los que su autoridad precautoria sea máxima.

\section{El frío de los gobiernos}

Estamos en un gran lío. Estábamos en la borrachera y despertamos. Pero los gobiernos, todo lo que intenta gobernar, administrar, gestionar, poner eficiencia, maximizar utilidades, duermen aún. Aunque el planeta está en emergencia climática, creen o simulan creer que el siglo XX se prolongará milagrosamente para ellos, rodeados de categorías intelectuales inútiles, conservadas con pasión como esos locos que guardan uñas y pelos. No hay alambres de púas ni muros ni planetas que les permitan salvarse fuera de esta tierra.

El presente es de aquellos que pueden vivir sin mercados ni supermercados. Pero también de los que no pueden vivir sin su cosmopolítica de cada día. 


\section{Yuri Carvajal Bañados}

\section{Bibliografía}

Arendt, Hannah. (2003). Conferencias sobre la filosofía política de Kant. Buenos Aires: Paidós.

Badie, Bertrand. (2019). "Asistimos a la reinvención del mundo y el sur tiene los hilos".

Entrevista en https://www.pagina12.com.ar/235405-asistimos-a-la-reivencion-del-mundo-y-elsur-tiene-los-hilos.

Bardet, Marie y Gago, Verónica. (2019). Insurreciones impuras y espiritualidad política. En http://lobosuelto.com/insurrecciones-impuras-y-espiritualidad-politica-marie-bardet-y-veronicagago/.

Benjamin, Walter. (2012). Escritos franceses. Buenos Aires-Madrid: Amorrortu.

Bolados, Paola. (2019). Paola Bolados, especialista en políticas ambientales, advierte sobre el peligro de no reconocer que la crisis política es socioambiental. Publicado el 6 de noviembre en https://www.elmostrador.cl/noticias/pais/2019/11/06/paola-bolados-especialista-en-politicas-

ambientales-advierte-sobre-el-peligro-de-no-reconocer-que-la-crisis-politica-es-socioambiental/.

Carvajal, Yuri. y Yuing, Tuillang. (2013). "Las estadísticas de salud no nacen de un repollo: jesuitas, aritméticas políticas, estigmergias y oligópticos”. En Salud Colectiva, 9(1):91-102.

Coccia, Emanuele. (2008). Filosofía de la imaginación. Averroes y el averroísmo. Buenos Aires; Adriana Hidalgo editora.

Crosby, Alfred. (2015). Ecological Imperialism. New York; Cambridge University Press, second edition.

Descola, Philippe. (2011). Más allá de naturaleza y cultura. Buenos Aires; Amorrortu

El Mostrador (2019). Manifestantes lanzan a carabineros un fósil de 66 millones de años.

Disponible en: https://www.elmostrador.cl/dia/2019/11/25/manifestantes-lanzan-a-carabinerosun-fosil-de-66-millones-de-anos/.(25 noviembre 2019).

Elizalde, Rafael. (1970). La sobrevivencia de Chile. Santiago de Chile; Ministerio de Agricultura.

Foucault, Michel. (2014). De los espacios otros. Conferencia dicada en el Cercle des études architecturals 1967. México: Fotocopioteca, s/v (43):5-10.

Haudricort, André George. (2019). El cultivo de los gestos entre Plantas, Animales y Humanos. Buenos Aires; Editorial Cactus.

Hurtubia, Jaime. (2019) La indignación de los jóvenes, la grave crisis climática y la COP25 que comienza. Publicado el1 diciembre 2019 en:https://www.elmostrador.cl/destacado/2019/12/01/laindignacion-de-los-jovenes-la-grave-crisis-climatica-y-la-cop25-que-comienza/. 


\section{Yuri Carvajal Bañados}

Instituto Milenio de Oceanografía (2019) (3 noviembre 2019). Científicos del IMO acusan miopía de las autoridades por cancelación de Cop: "no hay dos crisis, hay una sola y es socioambiental". Publicado el 3 de noviembre de 2019 https://www.elmostrador.cl/cultura/2019/11/03/cientificos-del-imo-acusan-miopia-de-la-elitepolitica-y-empresarial-por-cancelacion-de-cop-no-hay-dos-crisis-hay-una-sola-y-essocioambiental/.

Latour, B. (2008). Reensamblar lo social. Una introducción a la teoría del actor-red. Buenos Aires; Manantial.

Lazzarato, Maurizio. (2019). Critique du concept de "Biopolitique". Conferencia pronunciada en VII Coloquio Latinoamericano de Biopolítica. Ontologías del Presente. Santiago de Chile. 30 de Septiembre de 2019.

Medina, Edén. (2013). Revolucionarios cibernéticos. Tecnología y política en el Chile de Salvador Allende. Santiago de Chile; LOM.

Mitchell, Timothy. (2011). Carbon Democracy. London; Verso.

Payàs, Gertrudis. (2018). Los Parlamentos hispano-mapuches, 1953-1803: textos fundamentales. Temuco; Ediciones de La Universidad Católica de Temuco.

Serres, Michel. (2004). El Contrato Natural. Valencia; Pre-Textos

Soto, José. (2019) ¿Por qué la Comisión Técnica del acuerdo constitucional debe cambiar?: una propuesta desde la historia de la ciencia y la tecnología. Publicado el 1 de diciembre 2019.

Disponible en https://escritosdeurgencia.home.blog/2019/12/01/por-que-la-comision-tecnica-delacuerdo-constitucional-debe-cambiar-una-propuesta-desde-la-historia-de-la-ciencia-y-latecnologia/.

Weiss, Peter. (2010). Persecución y asesinato de Jean Paul Marat, respresentado por el grupo de actores del Hospicio de Charenton bajo la dirección del señor de Sade (1964). Buenos Aires: Adriana Hidalgo editora.

Yáñez, Juan (coord.). (2018). Gobernar es Alimentar. Discursos, Legislación y Políticas de Alimentación Popular, Chile, 1900-1950. Valparaíso; América en Movimiento. 